(2) Open Access Full Text Article

\title{
Agreement of swept-source and spectral-domain optical coherence-tomography retinal thickness measurements in neovascular age-related macular degeneration
}

This article was published in the following Dove Press journal:

Clinical Ophthalmology

\author{
Daren Hanumunthadu' \\ Tomas Ilginis' \\ Kamaljit S Balaggan ${ }^{1,2}$ \\ Praveen J Patel' \\ On behalf of the DOCS \\ team \\ 'NIHR Biomedical Research \\ Centre, Moorfields Eye Hospital \\ NHS Foundation Trust and \\ University College London \\ Institute of Ophthalmology, \\ London, ${ }^{2}$ Wolverhampton and \\ Midland Counties Eye Infirmary, \\ Wolverhampton, UK
}

Correspondence: Praveen J Patel Moorfields Eye Hospital NHS Foundation Trust, 162 City Road, London ECIV 2PD, UK

Tel +44207253 34II

Fax +44 2076086925

Email praveen.patel@moorfields.nhs.uk

\section{Introduction}

Changes in macular thickness measurements in neovascular age-related macular degeneration (nAMD) are thought to reflect disease activity, and can be used to guide treatment with antiangiogenic agents. ${ }^{1}$ Both spectral-domain optical coherence tomography (SD-OCT) and the more recently introduced swept-source optical coherence tomography (SS-OCT) have onboard segmentation algorithms that deliver automated retinal thickness measurements. Agreement between OCT derived macular thickness measurements is critical for monitoring of patients if these modalities are to be used interchangeably. This prospective cross-sectional study sought to determine the limits of agreement between SD-OCT (Spectralis; Heidelberg Engineering) and SS-OCT (DRI OCT-1 Atlantis; Topcon Medical Systems) in patients with nAMD.

\section{Methods}

This study formed part of the Distance of Choroid Study (DOCS) at Moorfields Eye Hospital, London in 2014. All subjects gave written informed consent prior to inclusion in the study. The study was approved by the local ethics committee (NRES Committee, South East Coast, Surrey) and adhered to the tenets set forth in the Declaration of Helsinki. Subjects aged 50-90 years with subfoveal choroidal neovascularization secondary to nAMD were included. Exclusion criteria included media opacity, previous ocular surgery (other than cataract surgery), significant ocular comorbidity, and diabetes mellitus. All patients underwent three Spectralis scans and three DRI OCT-1 scans in the same imaging session. The Spectralis scan was a macular volume scan consisting of a 25-line horizontal-line scan (512 A scan per B scan) in enhanced depthimaging mode. The DRI OCT- 1 scan consisted of a $12 \times 9 \mathrm{~mm}$ raster scan centered on the fovea. Automated retinal thickness measurements of the Early Treatment Diabetic Retinopathy Study were obtained using proprietary software on both SD-OCT (version 3.1) and SS-OCT (version 9.30).

\section{Results}

A total of 36 eyes of 36 patients with nAMD were included in the study. Subject characteristics are summarized in Table 1. Bland-Altman analysis showed low agreement between OCT-derived macular thickness measurements, with mean difference 
Table I Subject characteristics of patients with neovascular agerelated macular degeneration

\begin{tabular}{|c|c|}
\hline Subject characteristics & \\
\hline Age (years) & $71.2 \pm 9.4$ \\
\hline \multicolumn{2}{|l|}{ Sex $(n, \%$ total $)$} \\
\hline Male & $22(6 I . I)$ \\
\hline Female & 14 (38.9) \\
\hline \multicolumn{2}{|l|}{ Laterality (n, \% total) } \\
\hline Left & $23(63.9)$ \\
\hline Right & $13(36.1)$ \\
\hline Visual acuity (ETDRS letter score) & $63.5 \pm 19.2$ \\
\hline \multicolumn{2}{|l|}{ Lens status ( $\mathrm{n}, \%$ total) } \\
\hline Phakic & $27(75)$ \\
\hline Pseudophakic & $9(25)$ \\
\hline Lesion size, $\mathrm{mm}^{2}$ (mean disk area $\pm \mathrm{SD}$ ) & $1.2 \pm 0.8$ \\
\hline \multicolumn{2}{|l|}{ Lesion type ( $\mathrm{n}, \%$ total) } \\
\hline Classic & $15(4 \mid .7)$ \\
\hline Occult & $21(58.3)$ \\
\hline Antiangiogenic treatment* history & $34(94.4)$ \\
\hline \multicolumn{2}{|l|}{ (over previous 6 months) (n, \% total) } \\
\hline Ranibizumab & $28(77.9)$ \\
\hline Aflibercept & $6(16.7)$ \\
\hline No previous treatment & $2(5.6)$ \\
\hline Mean number of intravitreal & 2.4 \\
\hline injections (over previous 6 months) & \\
\hline
\end{tabular}

Notes: *Treatment with anti-VEGF agents. Data are presented as mean \pm SD unless otherwise specified.

Abbreviation: ETDRS, Early Treatment Diabetic Retinopathy Study. ranging from $18.2 \mu \mathrm{m}$ (A7) to $77.6 \mu \mathrm{m}$ (A2) (Figure 1). The $95 \%$ limits of agreement of the central macular subfield (A1) were $-20.5 \mu \mathrm{m}$ to $156.3 \mu \mathrm{m}$. There was a correlation between the magnitude of the retinal thickness measurement and the degree of variation between SD-OCT and SS-OCT for the A1 subfield (Spearman's correlation coefficient 0.59, $P=0.02$ ), suggesting that the variation in OCT derived metrics was perhaps more evident in those with more active disease. Given this association, it is possibly more appropriate to express the limits as a ratio after logarithmic transformation (95\% limits of agreement $0.97-1.74$ ), indicating that the SD-OCT measurements can be between 3\% smaller and $74 \%$ larger than SS-OCT central macular subfield-thickness measurements. ${ }^{2}$

\section{Discussion}

This analysis suggests there is surprisingly limited level of agreement between SD-OCT- and SS-OCT-derived retinal thickness measurements in subjects with nAMD included in our study. Alteration in foveal structure due to developing choroidal neovascularization, changes in foveal centration

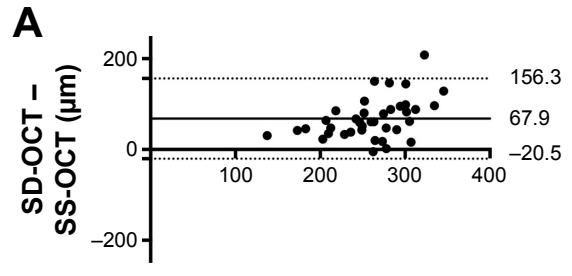

Mean retinal thickness of A1 macular subfield $(\mu \mathrm{m})$

D

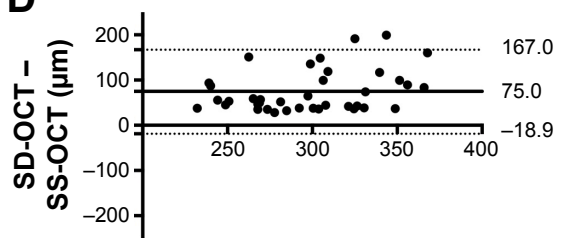

Mean retinal thickness of A4 macular subfield $(\mu \mathrm{m})$

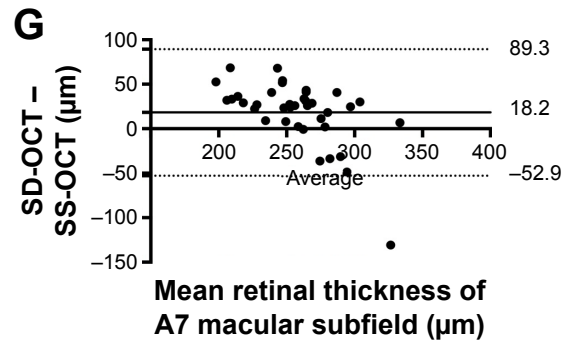

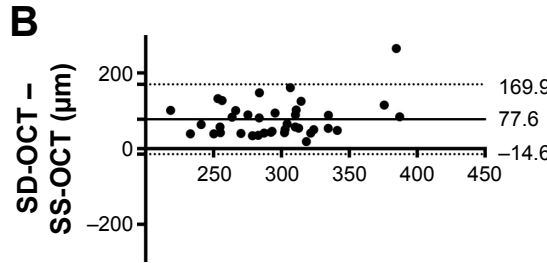

Mean retinal thickness of A2 macular subfield $(\mu \mathrm{m})$
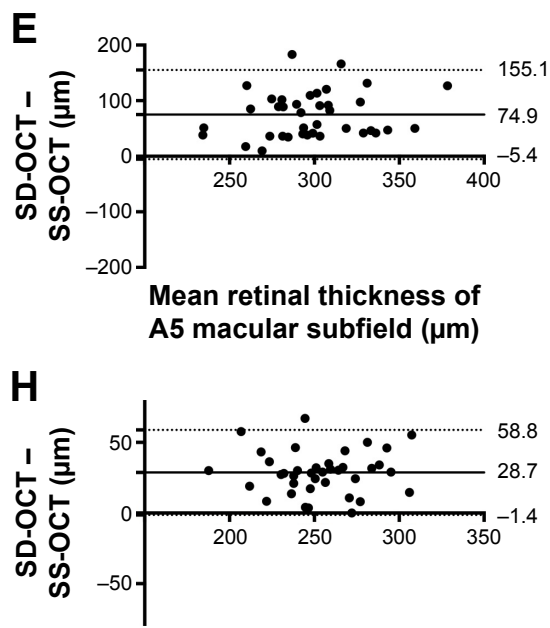

Mean retinal thickness of A8 macular subfield $(\mu \mathrm{m})$

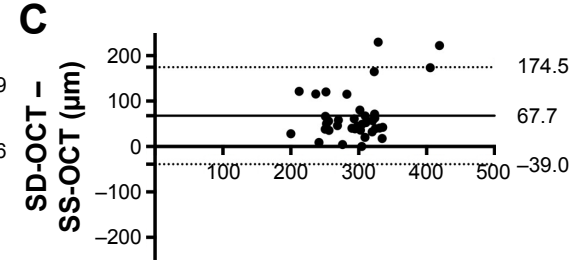

Mean retinal thickness of A3 macular subfield $(\mu \mathrm{m})$

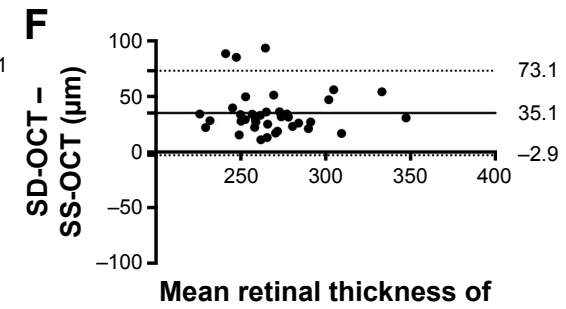

A6 macular subfield $(\mu \mathrm{m})$

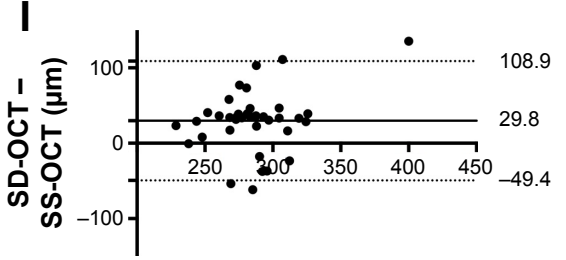

Mean retinal thickness of A9 macular subfield $(\mu \mathrm{m})$

Figure I Bland-Altman analysis comparing the mean difference between spectral-domain and swept source optical coherence tomography macular thickness measurements in neovascular age related macular degeneration.

Notes: Mean difference (bold line) and 95\% limits of agreement (LoA; dotted lines) between mean automated retina thickness measurements of Early Treatment Diabetic Retinopathy Study (ETDRS) subfields (A) Al central: mean 67.9 45 .I $\mu \mathrm{m}$; LoA: $-20.5 \mu \mathrm{m}$ to $156.3 \mu \mathrm{m}$; (B) A2 inner superior: mean $77.6 \pm 47.1 \mu \mathrm{m}$; LoA -14.6 $\mu \mathrm{m}$ to $169.9 \mu \mathrm{m}$;

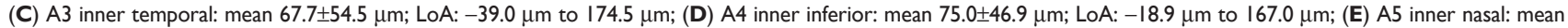

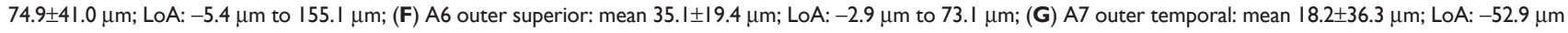
to $89.3 \mu \mathrm{m}$; (H) A8 outer inferior: mean $28.7 \pm 15.4 \mu \mathrm{m}$; LoA: $-1.4 \mu \mathrm{m}$ to $58.8 \mu \mathrm{m}$; (I) A9 outer nasal: mean 29.8 $40.4 \mu \mathrm{m}$; LoA: $-49.4 \mu \mathrm{m}$ to $108.9 \mu \mathrm{m}$. 
and segmentation error may affect retinal thickness measurements in nAMD. ${ }^{3-5}$ The Spectralis and DRI OCT function at different imaging-light wavelengths $(840 \mathrm{~nm}$ and $1,050 \mathrm{~nm}$, respectively) with different spatial resolution $(7 \times 14 \mu \mathrm{m}$ and $8 \times 20 \mu \mathrm{m}$, respectively). Differences in segmentation algorithms, particularly in the location of the inner retinal boundary, have the potential to alter automated retinal thickness measurements. ${ }^{6}$ Further analysis with a larger study population is required to evaluate the disparity between retinal thickness measurements. We suggest that the use of absolute retinal thickness measurements in nAMD can only be interpreted in the context of the OCT technology used. Differences in the central macular subfield measurements appeared greatest at larger retinal thicknesses, where disease activity was presumably higher. Clinicians should be aware of this variability, and should consider utilization of a single form of OCT during monitoring of patients with nAMD to prevent conflation of variation in disease activity and different forms of OCT technology.

\section{Acknowledgments}

This work was funded by SalutarisMD and supported by the National Institute of Healthy Research (NIHR) Biomedical Research Centre at Moorfields Eye Hospital National
Health Service (NHS) Foundation Trust and UCL Institute of Ophthalmology. The views expressed are those of the authors, and not necessarily those of the NHS, the NIHR, or the Department of Health.

\section{Disclosure}

The authors report no conflicts of interest in this work.

\section{References}

1. Keane PA, Liakopoulos S, Jivrajka RV, et al. Evaluation of optical coherence tomography retinal thickness parameters for use in clinical trials for neovascular age-related macular degeneration. Invest Ophthalmol Vis Sci. 2009;50(7):3378-3385

2. Bland JM, Altman DG. Measuring agreement in method comparison studies. Stat Methods Med Res. 1999;8(2):135-160.

3. Mansouri K, Medeiros FA, Tatham AJ, Marchase N, Weinreb RN. Evaluation of retinal and choroidal thickness by swept-source optical coherence tomography: repeatability and assessment of artifacts. Am J Ophthalmol. 2014;157(5):1022-1032.

4. Midena E, Radin PP, Pilotto E, Ghirlando A, Convento E, Varano M. Fixation pattern and macular sensitivity in eyes with subfoveal choroidal neovascularization secondary to age-related macular degeneration: a microperimetry study. Semin Ophthalmol. 2004;19(1-2):55-61.

5. Kim M, Lee S, Han J, Yu SY, Kwak H. Segmentation error and macular thickness measurements obtained with spectral-domain optical coherence tomography devices in neovascular age-related macular degeneration. Indian J Ophthalmol. 2013;61(5):213-217.

6. Pierre-Kahn V, Tadayoni R, Haouchine B, Massin P, Gaudric A. Comparison of optical coherence tomography models OCT1 and Stratus OCT for macular retinal thickness measurement. Br JOphthalmol. 2005, 89(12):1581-1585.
Clinical Ophthalmology

\section{Publish your work in this journal}

Clinical Ophthalmology is an international, peer-reviewed journal covering all subspecialties within ophthalmology. Key topics include: Optometry; Visual science; Pharmacology and drug therapy in eye diseases; Basic Sciences; Primary and Secondary eye care; Patient Safety and Quality of Care Improvements. This journal is indexed on

Submit your manuscript here: http://www.dovepress.com/clinical-ophthalmology-journal

\section{Dovepress}

PubMed Central and CAS, and is the official journal of The Society of Clinical Ophthalmology (SCO). The manuscript management system is completely online and includes a very quick and fair peer-review system, which is all easy to use. Visit http://www.dovepress.com/ testimonials.php to read real quotes from published authors. 